\title{
CREATING AN INTERACTIVE TOOL FOR STUDENT COMMUNICATION: LESSONS LEARNT
}

\author{
David Cutting ${ }^{1}$, Andrew McDowell ${ }^{1}$, Neil Anderson ${ }^{1}$, Paul Sage ${ }^{1}$, Matthew Collins ${ }^{1}$, \\ \& Angela Allen \\ ${ }^{1} \mathrm{Dr}$. \\ School of Electronics, Electrical Engineering and Computer Science, \\ Queen's University Belfast (United Kingdom)
}

\begin{abstract}
Following significant success in the use of so-called "backchannel" tools in building student engagement within the School of Electronics, Electrical Engineering and Computer Science at Queen's University Belfast a situation arose in 2018 where our choice of provider closed down. We attempted to use other available off-the-shelf tools but for various reasons these were not widely adopted. At the end of 2018 we decided to implement our own student-facing communication, question and, chat tool for students and lecturing staff to use. Called QChan the system went live, while still under development, to classes as large as 400 in size in January 2019. Developing a system to encourage use, be easily accessible and yet secure and robust enough to withstand experimenting computer science students was something of a challenge. In 2020, QChan is widely used in our school and has been a driver to better student engagement. We continue to develop QChan and also analyse it and the other platforms' content to better understand how to consistently engage with students.
\end{abstract}

Keywords: Backchannel, engagement, chat, technology.

\section{Introduction}

The engagement of students as active participants in teaching is a key topic of interest especially as we seek to move from the "chalk and talk" didactic form of delivery to one of discussion and giving students agency in their own learning. Key to this is breaking down the barriers, especially in the increasingly common large cohorts (Gibbs \& Jenkins, 2014) found in universities. One such approach to encourage interrogative questioning is the use of "back channels" which allow interactions between staff and students alongside the traditional lecture (Baron, et al. 2016). Facilitating engagement in this fashion is seen to both increase the volume of questions from the class to staff but can also facilitate intra-student communication to build a community (Bry, Gehlen-Baum, \& Pohl, 2011; Fortes \& Tchantchane, 2010; Yong-Su Pohl \& Gehlen-Baum, 2011).

We, at Queen's University Belfast in the School of Electronics, Electrical Engineering and Computer Science, make use of such backchannel approaches and have been keenly interested in their adoption and effectiveness (McDowell et al, 2019-1).

Initially we used a freely available product called TodaysMeet in providing backchannel support. This was a web-based totally anonymous system where anyone with the room code could join and comment. Although engagement was good there were some issues with inappropriate comments being made which, due to the anonymous nature, could not be sourced back to any individual. TodaysMeet was then withdrawn by the company providing it.

The school then moved onto using Microsoft Teams for class-based questioning. This is completely tied to the user accounts and all questions/comments are seen with the full name of the person posting them. The take-up of teams was very low with few students using it to engage, and our research pointed to the issue being a lack of any sort of anonymity (McDowell et al, 2019-2; McDowell et al, 2019-3). We therefore decided to address this issue and look towards an in-house solution. 


\section{Requirements}

Clearly the issues facing the two previous platforms were contradictory; anonymity led to inappropriate untraceable content and no anonymity led to a complete lack of engagement. The solution we determined to try was that of "pseudonymity" where each account was distinct and tied to student email but a chosen nickname was all that was visible to other students and, unless specifically requested, staff. Students were clearly told that they must act appropriately and that all comments could, if necessary, be traced back, but otherwise they were anonymous within the cohort.

This, along with a review of the existing systems and multiple conversations with stakeholder staff, led to the following requirements for the system:

- Pseudonymity of users within rooms

- Multiple rooms (for example for a module)

- Different access models (join by code, must be added, open to public)

- Different posting models (open forum where anyone can see any post by anyone or question channel where only staff members can see posts from students)

- Mobile-first development (the vast majority of students will use their mobile devices to access)

- Single-link login (saves another username and password or any federated login setup)

- No specialist software or install required (web based)

- Batch enrolment of students by staff

\section{Development}

With these requirements in mind initial development took place in December 2018 with acceptance testing in very early 2019. The first cohorts of students to be enrolled began to use the system (QChan) in mid-January 2019. The decision was made to fast-track development and deploy live to the students and then review and develop iteratively as needed.

The initial deployment worked well, and student engagement was very good in early classes. Several bugs were quickly identified (and exploited!) by computer science students including allowing scrolling and flashing text in nicknames. A special "break this" room was created and students who wished to explore the confines of the system invited to do whatever they wished in there and report back. Several high-quality items of feedback and suggestions were received and incorporated into the functions. An example of QChan in operation can be seen in Figure 1.

\section{Conclusion and future work}

QChan has now been successfully used at Queen's University Belfast by a number of staff over one and a half academic years. During that time many hundreds of students have been connected simultaneously and nearly 4,000 messages have been sent. The pseudononymous nature appears to have increased engagement while at the same time only requiring that two students were looked up and sent warning emails. Clear messaging that this was possible has largely removed the issues that were present with the fully-anonymous TodaysMeet.

QChan (https://qchan.io) is still under active development and we welcome any other higher or further education institutions that may like to use QChan or become development partners to get in touch through the corresponding author Dr David Cutting (d.cutting@qub.ac.uk). We are actively now analysing the messages sent through the different platforms including sentiment analysis to better understand how to effectively use these tools to build better and consistent engagement. 
Figure 1. Example QChan Mobile Interface with Room Menu and Student Engagement.

\section{QChan}

\section{Rooms}

\section{CSC1023 1819 [Today] [All] \\ Chat Room - Open [ edit leave ], last message 2019- 01-25 09:02:01}

CSC2046 1819 [Today] [All]

Chat Room - Open [ edit leave ], last message 201901-25 13.19.55

CSC1021 1819 [Today] [All]

Chat Room - Open [ edit ], last message 2019-01-25 $14: 26: 41$

\section{Create a Room}

Room Name

Name of Room

Room Type

Chat Room

Create Room

\section{QChan: CSC1021 1819}

System.out.printIn("Help"): If you wanted to loop back to ask the user to enter a pizza if an incorrect. input was entered, how would you do that?

partygirl: when will you be uploading the lecture videos?

I don't understand: Can you slow down pls

Andrew - Lecturer: Hi Folks, todays video lecture is now available on YouTube - just a heads up that you can subscribe to me there and get notifications when I upload new lecture videos.

Java good time: hi

Cass: hiva

Jake Paul : Heya

6figuresiwasonly4: Thank god

MeganAkaBlogger $\mathbf{x}$ : This is very heloful

How do you comment out multiple lines of code in one go?

Message...

\section{References}

Baron, D., Bestbier, A., Case, J., \& Colier-Reed, B. (2016). Investigating the effects of a backchannel on university classroom interactions: A mixed-method case study. Computers \& Education, 94, 61-76.

Bry, F., Gehlen-Baum, V., \& Pohl, A. (2011). Promoting awareness and participation in large class lectures: The digital backchannel backstage. IADIS International Conference Esociety, 27-34. Retrieved from http://pms.ifi.lmu.de

Fortes, P. C., \& Tchantchane, A. (2010). Dealing with Large Classes: A Real Challenge. Procedia Social and Behavioral Sciences, 8, 272-280. https://doi.org/10.1016/J.SBSPRO.2010.12.037

Gibbs, G., \& Jenkins, A. (2014). Teaching large classes in higher education: How to maintain quality with reduced resources. Routledge.

McDowell, A., Cutting, D., Allen, A., \& Sage, P. (2019-2). Anonymous vs. Non-Anonymous Backchannels: The Good, The Bad and the Ugly. Abstract from Higher Education Academy STEM Conference, Birmingham, United Kingdom. 
McDowell, A., Cutting, D., Sage, P., Allen, A., \& McGowan, A. (2019-1). Promoting learner engagement: measuring and characterising learner engagement using a collaborative online learning tool. Paper presented at International Conference on Education and New Developments, Porto, Portugal.

McDowell, A., Cutting, D., Sage, P., Allen, A., \& McGowan, A. (2019-3). Backchannel in Large Learner Cohorts - Does Anonymity Matter? A Comparative Study. Paper presented at Education and Information Systems, Technologies and Applications, Orlando, United States.

Yong-Su Pohl, A., \& Gehlen-Baum, V. (2011). Introducing Backstage - a digital backchannel for large class lectures. Interactive Technology and Smart Education, 8(3), 186-200. 